\title{
Comparison Between LURR and State Vector Analysis Before Strong Earthquakes in Southern California Since 1980
}

\author{
Yongxian Zhang, ${ }^{1,2}$ Yonguia Wu, ${ }^{1}$ Xiangchu Yin, ${ }^{2,3}$ Keyin Peng, ${ }^{1,2}$ Langping Zhang, ${ }^{2}$ \\ Aiqin $\mathrm{Yu}^{4}$, and XiaOtao $\mathrm{ZHANG}^{3}$
}

\begin{abstract}
There are seven strong earthquakes with $\mathrm{M} \geq 6.5$ that occurred in southern California during the period from 1980 to 2005. In this paper, these earthquakes were studied by the LURR (Load/Unload Response Ratio) method and the State Vector method to detect if there are anomalies before them. The results show that LURR anomalies appeared before 6 earthquakes out of 7 and State Vector anomalies appeared before all 7 earthquakes. For the LURR method, the interval between maximum LURR value and the forthcoming earthquake is 1 to 19 months, and the dominant mean interval is about 10.7 months. For the State Vector method, the interval between the maximum modulus of increment State Vector and the forthcoming earthquake is from 3 to 27 months, but the dominant mean interval between the occurrence time of the maximum State Vector anomaly and the forthcoming earthquake is about 4.7 months. The results also show that the minimum valid space window scale for the LURR and the State Vector is a circle with a radius of $100 \mathrm{~km}$ and a square of $3^{\circ} \times 3^{\circ}$, respectively. These results imply that the State Vector method is more effective for short-term earthquake prediction than the LURR method, however the LURR method is more effective for location prediction than the State Vector method.
\end{abstract}

Key words: LURR, state vector, characteristics of anomaly, earthquake prediction, Southern California.

\section{Introduction}

LURR (Load/Unload Response Ratio) is an earthquake prediction method put forward by Yin (1987). LURR (Load/Unload Response Ratio) is defined as (YIN, 1987)

$$
Y=X^{+} / X^{-},
$$

${ }^{1}$ China Earthquake Networks Center, Beijing 100045, China. E-mail: yxzhseis@sina.com; wuyongj@mails.gucas.ac.cn; pengkeyin@seis.ac.cn

2 LNM, Institute of Mechanics, Chinese Academy of Sciences, Beijing 100080, China.

E-mail: yin@lnm.imech.ac.cn; zhanglp@lnm.imech.ac.cn

3 Institute of Earthquake Science, China Earthquake Administration, Beijing 100036, China.

E-mail: yinxc@btmail.net.cn; qdzxt_116@163.com

${ }^{4}$ China Earthquake Disaster Prevention Center, Beijing 100029, China. E-mail: yuaiqin2006@126.com 
where $X^{+}$and $X^{-}$are the response rates during loading and unloading measured by some method. The intention of this concept is that when a seismogenic system is in a stable state, its response to loading is nearly the same as its response to unloading, whereas when the system is in an unstable state, the response to loading is stronger than that to unloading.

Based on the theory of LURR and its recent development (YIN, 1987; YIN and YIN, 1991; YIN et al., 1995, 2000; WANG et al., 1999; Mora et al., 2000a,b, 2002), spatial and temporal variation of $Y / Y_{c}$ in Southern California and its adjacent area $\left(32^{\circ} \mathrm{N}\right.$ to $40^{\circ} \mathrm{N}$, $114^{\circ} \mathrm{W}$ to $125^{\circ} \mathrm{W}$ ) during the period from 1980 through March, 2002 has been studied (Zhang et al., 2004). Here $Y_{c}$ is the critical value of LURR that depends on the number of earthquakes under different specified confidence levels (ZHUANG and YIN, 1999). For instance, at the confidence level of $90 \%, Y_{c}$ is equal to 3.18 if the number of earthquakes in the time and space window is 20 , which means that $Y$ should be equal to or greater than 3.18 for the medium to be considered in an unstable state when the number of earthquakes is 20 . For the confidence level of $99 \%, Y_{c}$ is 7.69 if the number of earthquakes in the specific time and space window is 20 . The greater the earthquake number is, the lower the $Y_{c}$ (critical value of LURR). Here we chose the confidence level as $99 \%$. The scanning results show that obvious $Y / Y_{c}$ anomalies occurred before 5 of the total 6 earthquakes with $\mathrm{M} \geq 6.5$, the area with $Y / Y_{c}$ anomalies is near the epicenters of the strong earthquakes, and the $Y / Y_{c}$ anomalies occur months to years prior to the earthquakes. After March, 2002,

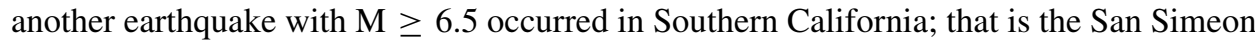
M $6.5\left(35.7^{\circ} \mathrm{N}, 121.1^{\circ} \mathrm{W}\right)$ earthquake on Dec. 22,2003 . In order to obtain the evolutionary process of LURR before this quake, ZHANG et al. $(2004,2006)$ calculated $Y / Y_{c}$ in Southern California with earthquake catalogue of ANSS from April 2002 to June 2004 under the same calculation parameters. The results show that the characteristic of LURR before the San Simeon earthquake is similar to the former ones.

In recent years, a new earthquake prediction method named State Vector was put forward by YIN et al. (2004a,b). Their results show that significant anomalies occurred several months prior to the Tangshan M 7.8 and Haicheng M 7.3 earthquakes. YU et al. (2004) confirmed the phenomena of State Vector anomaly before rock failure by a rock mechanical test. Wu et al. (2006) applied this method to study 25 strong earthquakes with $M \geq 6.8$ in the China mainland and obtained the results that there are obvious State Vector anomalies three years prior to 19 out of 25 strong earthquakes and among these 19 strong earthquakes there are obvious state vector anomalies 60 days before 10 of them. These results show considerable promise for short-term earthquake prediction.

Is the State Vector effective in other tectonic regions? What is the difference between the characteristics of the LURR and the State Vector? In order to obtain the answers, we apply the State Vector method to the Southern California region to see if there are obvious anomalies before strong earthquakes in this region, and compare the characteristics of State Vector anomalies to those of LURR.

The earthquake catalogue we used in this paper is downloaded from the web site http://www.ncedc.org/anss/catalog-search.html, which is the ANSS (Advance National Seismic System) composite earthquake catalogue. 


\section{Method to Calculate LURR and State Vector}

\section{1. $L U R R$}

LURR (Load/Unload Response Ratio) is an approach to testing for crustal criticality put forward by YIN (1987). Its hypothesis is that an earthquake is the failure or instability of the focal media or seismogenic system. When the system is in a stable state, its response to loading is nearly the same as its response to unloading, whereas when the system is in an unstable state, the response to loading is more sensitive than that to unloading (YIN, 1987; YIN and YIN, 1991; YIN et al., 1995, 2000). YIN (1987) defined LURR in formula (1).

In the LURR theory, $Y$ is defined directly by means of seismic energy as follows:

$$
Y_{m}=\frac{\left[\sum_{i=1}^{N^{+}} E_{i}^{m}\right]_{+}}{\left[\sum_{i=1}^{N^{-}} E_{i}^{m}\right]_{-}},
$$

where $E$ denotes seismic energy which can be calculated according to the GutenbergRichter formula (KanAmori and Anderson, 1975; Bullen and Bolt, 1985), the "+" sign means loading and " - " means unloading, $m=0$ or $1 / 3$ or $1 / 2$ or $2 / 3$ or 1 . When $m=1, E^{\mathrm{m}}$ is exactly the energy itself. For $m=1 / 2, E^{\mathrm{m}}$ denotes the Benioff strain. For $m=1 / 3$ and $2 /$ $3, E^{\mathrm{m}}$ represents the linear scale and area scale of the focal zone, respectively. For $m=0, Y$ is equal to $N^{+} / N^{-}$, and $N^{+}$and $N^{-}$denote the number of earthquakes which occur during the loading and unloading periods. In this paper, $m$ is chosen as $1 / 2$, which means that $Y$ is determined by the ratio of Benioff strain during the loading period over the unloading period, and $Y_{c}$ is chosen as $Y$ value under the confidence level of $99 \%$.

Earthquake energy $E_{i}$ in formula (2) is related to magnitude by the following formula (GutENBERG and Richter, 1956)

$$
\log _{10} E_{i}=11.8+1.5 M_{i}
$$

where $M_{i}$ is the magnitude of $i$-th earthquake, and the unit of energy $E_{i}$ is erg $\left(\times 10^{-5} J\right)$.

The periods of loading and unloading are determined by calculating perturbations in the Coulomb Failure Stress $\triangle C F S$ induced by earth tides (YIN et al., 1995; Zhang et al., 2006). We divided the Southern California region into 11 units (ZHANG et al., 2004, 2006), and in each of them the stress distribution (ZовАск, 1992) and fault parameters SCECDC (Southern California Data Center) are generally uniform.

In order to speed up the calculations and avoid the perturbation caused by outstanding earthquakes, we chose magnitude thresholds according to the linear part of the Gutenberg-Richter relation in each unit area.

According to the relationships between the spatial window, time window and the magnitude obtained in the earthquake case studies conducted by YIN et al. (2002a,b) and ZHANG et al. (2005), when the spatial window is chosen as a circular region with the radius of about $100 \mathrm{~km}$, and the time window is one year, the magnitude of the forthcoming earthquake could be predicted as larger than M 6. In this region a value of 
$Y / Y_{c}$ (LURR/critical LURR) was calculated for a specific time window (1 year), and the time step is 1 month. The circle center was moved step by step in both latitude and longitude by increments of 0.25 degrees so the contour of $Y / Y_{c}$ in each month could be obtained.

\subsection{State Vector}

The State Vector is an idea from statistical physics (REICHL, 1980). YIN et al. (2004b) extended this idea to describe the evolution of the damage of rock specimens. The whole specimen is divided into $n$ regions. The AE (Acoustic Emission) energy or AE event rate at time $t_{k}$ in region $i$ denotes the $i$-th component $e_{i}$, and the whole $n$ components construct a state vector $\vec{V}_{t}$ of $n$ dimensions (YIN et al., 2004b).

$$
\vec{V}_{t}=\left(e_{1}(t), e_{2}(t), \ldots, e_{n}(t)\right) .
$$

In earthquake prediction practice, $e_{i}$ in formula (4) is defined as the sum of the logarithms of each earthquake energy $E_{j}$ in the $i$-th subsquare during the period from $t-T$ to $t$, as the following

$$
e_{i}(t)=\left.\sum_{j=1}^{k} \lg E_{j}\right|_{t-T} ^{t} .
$$

Here $T$ refers to the time window for calculation, and the earthquake energy $E_{j}$ is calculated by formula (3).

Figure 1 illustrates the schematic diagram of time window $T$ and time step $\Delta t$ in the calculation.

In our study, the time widow is chosen as $T=1$ year and the time step is $\Delta t=30$ days.

The following parameters associated with State Vector could be obtained:

a. Modulus of the State Vector at time $t$

$$
M_{t}=\left|\vec{V}_{t}\right|
$$

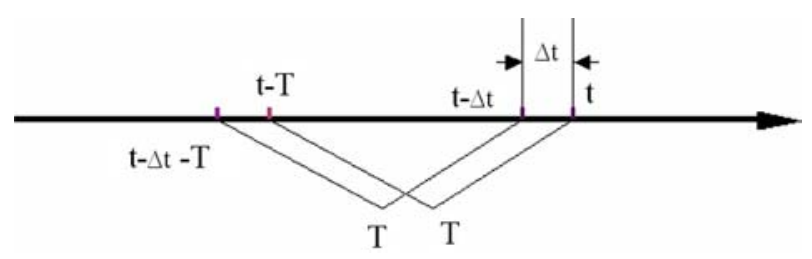

Figure 1

Schematic diagram of time window $T$ and time step $\Delta t$. 
b. Modulus of the increment of the State Vector during time $t$ - $\Delta t$ to $t$

$$
\Delta M_{t-\Delta t, t}=\left|\Delta \vec{V}_{t-\Delta t, t}\right| \text {. }
$$

c. Angle between State Vectors from time $t-\Delta t$ to $t$

$$
\varphi_{t-\Delta t, t}=\arccos \left(\frac{\vec{V}_{t-\Delta t} \cdot \vec{V}_{t}}{V_{t-\Delta t} V_{t}}\right) .
$$

When $n=3$, the State Vector could be illustrated by 3D phase shown in Figure 2. $\vec{V}_{1}$ stands for the State Vector at time $t_{1}, \vec{V}_{2}$ is the State Vector at time $t_{2}$, and $\vec{V}_{3}$ is the State Vector at time $t_{3} . \Delta \vec{V}_{12}$ is the increment of the State Vector from $t_{1}$ to $t_{2}$, and $\Delta \vec{V}_{23}$ is the increment of the State Vector from $t_{2}$ to $t_{3} . \varphi_{12}$ is the angle between $\vec{V}_{1}$ and $\vec{V}_{2}$.

In order to study the evolution of the State Vector before strong earthquakes in Southern California, we chose a square region of $m^{\circ} \times m^{\circ}$ subsquares with the epicenter of the target strong earthquake at the center, where $m$ is varied from 3 to 11 to obtain the result with the best goodness of fit. To determine the best goodness of fit, we calculate the parameters of State Vector in different space scales. If obvious variation occurs before the quake and there are no other major changes in other periods (say, the change of the parameter is larger than two times the standard deviation), we take the space scale as the critical scale for the seismogenic region (Wu et al., 2006).

Considering the completeness of the earthquake catalogue and avoiding the turbulence of the result affected by major earthquakes, we chose the cutoff of the magnitude as $2.0 \leq m_{j} \leq m_{0}-0.5$, where $m_{0}$ is the magnitude of the target earthquake.

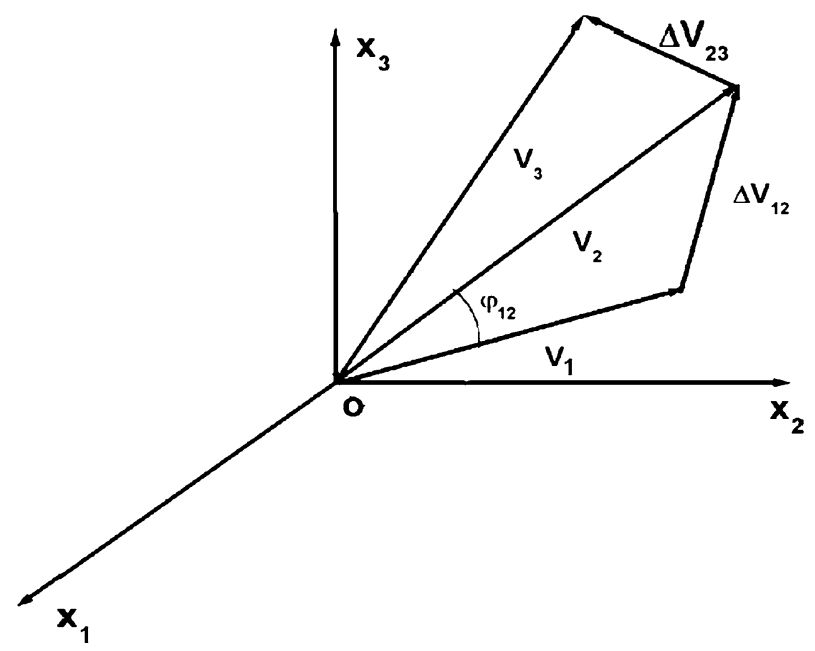

Figure 2

State Vector in 3D phase. 


\section{Characteristics of the LURR Anomaly before Strong Earthquakes in Southern California}

According to ZHANG et al. (2004, 2006), among the seven strong earthquakes with $M \geq 6.5$ in Southern California since 1980, obvious LURR anomalies occurred prior to six of them. The characteristics of the LURR anomalies are listed in Table 1.

We can see from Table 1 that except for the Coalinga earthquake in 1983, $Y / Y_{c}$ anomalies occurred before the other six earthquakes in Southern California. The forthcoming strong earthquake occurred 1 to 19 months after the time when $Y / Y_{c}$ reached its peak value. According to the common conception of long-term (several years to ten years), medium-term (one year to several years), short-term (several months) and imminent (several days to ten days) earthquake prediction in China (MEI et al., 1993), Table 1 implies that LURR is valid for medium-term to short-term prediction. The dominant $\Delta t$ is from 8 to 13 months, and the mean value is about 10.7 months. This might be applied to earthquake forecasting in this region.

Table 1 also shows that the distance between the epicenter of the forthcoming earthquake and the maximum $Y / Y_{c}$ point is from 0 to $200 \mathrm{~km}$, and the dominant $\Delta(\mathrm{km})$ is about $100 \mathrm{~km}$. This implies that if the location of the maximum $Y / Y_{c}$ point is detected, we might forecast that there probably will be a strong earthquake with $\mathrm{M} \geq 6.5$ occurring within $200 \mathrm{~km}$ from the maximum $Y / Y_{c}$ point.

\section{Characteristics of the State Vector Anomaly before Strong Earthquakes in Southern California}

For the seven strong earthquakes in Southern California in Table 1, we calculated the time series of the modulus of the State Vector, the modulus of the increment of

Table 1

Characteristics of $Y / Y_{c}$ before strong earthquakes in Southern California since 1980.

\begin{tabular}{lllllr}
\hline Date & \multicolumn{1}{c}{ Epicenter and location } & $\begin{array}{c}\text { Magnitude } \\
/ \Delta(\mathrm{km})\end{array}$ & Max $Y / Y_{c}$ & $\begin{array}{c}\text { Lasting time } \\
\text { of anomalous } Y / Y_{c} \\
\text { (month) }\end{array}$ & $\begin{array}{c}\Delta \tau \\
\text { (month) }\end{array}$ \\
\hline 1983.5 .2 & $\left(36.23^{\circ} \mathrm{N}, 120.32^{\circ} \mathrm{W}\right)$ Coalinga & $6.7 /$ None & None & None & None \\
1987.11 .24 & $\left(33.01^{\circ} \mathrm{N}, 115.85^{\circ} \mathrm{W}\right)$ Superstition Hills & $6.6 / 0$ & 1.4 & 21 & 11 \\
1989.10 .18 & $\left(37.04^{\circ} \mathrm{N}, 121.88^{\circ} \mathrm{W}\right)$ Loma Prieta & $7.0 / 100$ & 1.2 & 24 & 10 \\
1992.6 .28 & $\left(34.20^{\circ} \mathrm{N}, 116.44^{\circ} \mathrm{W}\right)$ Landers & $7.3 / 100$ & 1.0 & 18 & 8 \\
1994.1 .17 & $\left(34.21^{\circ} \mathrm{N}, 118.54^{\circ} \mathrm{W}\right)$ Northridge & $6.6 / 200^{*}$ & 1.2 & 25 & 13 \\
1999.10 .16 & $\left(34.59^{\circ} \mathrm{N}, 116.27^{\circ} \mathrm{W}\right)$ Hector Mine & $7.1 / 100$ & 1.4 & 15 & 19 \\
2003.12 .22 & $\left(35.7^{\circ} \mathrm{N}, 121.1^{\circ} \mathrm{W}\right)$ San Simeon & $6.5 / 50$ & 1.4 & 15 & 19 \\
\hline
\end{tabular}

Notes: $\Delta(\mathrm{km})$ is the distance between the forthcoming earthquake and the maximum $Y / Y_{c}$ point.

$\Delta \tau$ is the interval between the occurrence time of the maximum $Y / Y_{c}$ anomaly and the occurrence time of the forthcoming earthquake.

* The distance between the maximum point of $\Delta M$ and the forthcoming 1994 earthquake is $200 \mathrm{~km}$, not $80 \mathrm{~km}$ as mentioned in the early paper (ZHANG et al., 2004). We corrected it in the later paper (ZHANG et al., 2006), but did not give the annotation. 
the State Vector, and the angle between the State Vectors according to formula (4) to (6).

Since the parameter of the angle between State Vectors does not show a regular feature before these earthquakes, we only discuss the characteristics of the modulus of the State Vector and the modulus of the increment of the State Vector in this paper.

Here we give examples of the evolution of the modulus of the State Vector and the modulus of the increment of the State Vector before the Coalinga earthquake.

Figure 3 shows the curve of $\Delta M$ with time before the Coalinga M 6.7 earthquake. For this earthquake we chose square regions with scales ranging from $3^{\circ} \times 3^{\circ}$ to $11^{\circ} \times 11^{\circ}$ with the epicenter of the Coalinga earthquake at the center. The curve with the scale of $3^{\circ} \times 3^{\circ}$ shows the obvious anomaly of the State Vector before the quake, so we take the region of $3^{\circ} \times 3^{\circ}(m=3)$ as the critical scale for the seismogenic region.

From this figure we can see that the maximum $\Delta M$ value occurred on Jan. 1, 1983, and the Coalinga earthquake occurred 4 months later on May 2, 1983. Two smaller peaks of $\Delta M$ appeared on May 1, 1980 and May 1, 1981 without earthquakes larger than M 6.5 occurring after them. However, what interests us is that, during the period from 1970 to May 2, 1983, two earthquakes of M $6.2\left(37.50^{\circ} \mathrm{N}, 118.81^{\circ} \mathrm{W}\right)$ and $\mathrm{M} 5.9\left(37.50^{\circ} \mathrm{N}\right.$, $118.81^{\circ} \mathrm{W}$ ) occurred on May 27, 1980 and Sept. 30, 1981, respectively. In fact, there were only these three earthquakes with $M \geq 5.9$ in this selected region since 1970 . What is the relationship between the two peak values and the M 6.2 and M 5.9 earthquakes? Are there any $\Delta M$ anomalies before smaller earthquakes like the two earthquakes of $M 6.2$ and M 5.9? We will study this phenomenon in the future.

For the modulus of the State Vector $M$, the result also shows positive prospect. Figure 4 shows the curve of $M$ with time before the Coalinga earthquake. From this figure, we can see that the maximum $M$ value occurred on April 1, 1983, and the Coalinga

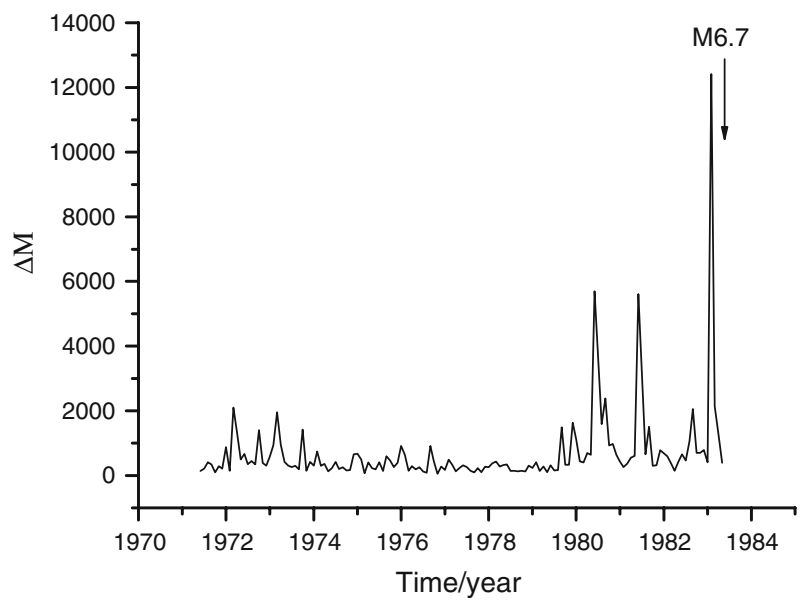

Figure 3

Evolution of the modulus of state vector increment before the Coalinga earthquake. 


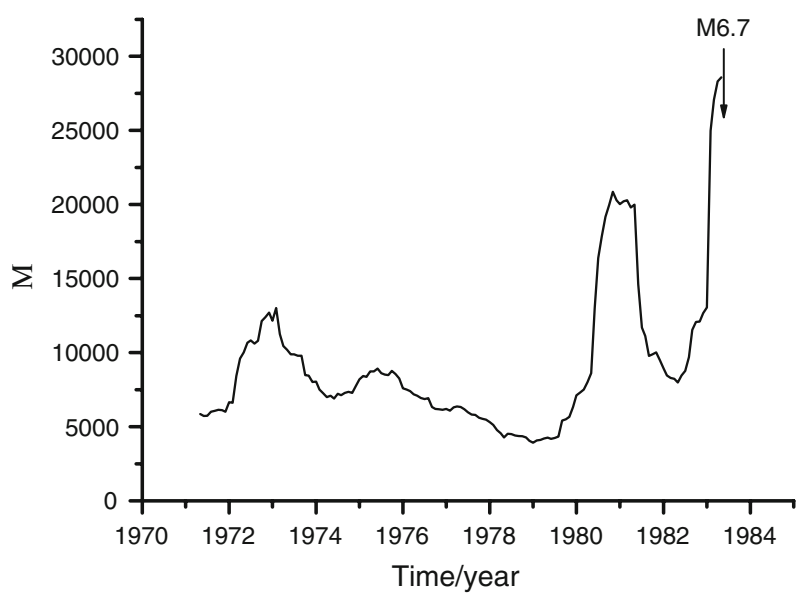

Figure 4

Evolution of the modulus of State Vector before the Coalinga Earthquake.

earthquake occurred 1 month later on May 2, 1983. For the second peak of $M$, which appeared on Oct. 1,1980 , there is a M 6.2 earthquake $\left(37.50^{\circ} \mathrm{N}, 118.81^{\circ} \mathrm{W}\right)$ that occurred on May 27, 1980, that did not occur after the peak. However, $M$ rises from the base value of about 13052 (on Jan.1, 1983) to 28591 (on April 1, 1983) before the M 6.2 earthquake. In other words, $M$ rises rapidly before strong earthquakes, however some earthquakes might occur after $M$ reaches the peak value, and others might occur before $M$ reaches the peak value.

The critical scale of $3^{\circ} \times 3^{\circ}$ shows the obvious $\Delta M_{\max }$ and $M_{\max }$ anomalies preceding the Coalinga earthquake. The $\Delta M_{\max }$ anomaly occurred on Jan. 1, 1983, about 4 months before the earthquake, and $M_{\max }$ occurred on April 1, 1983, about 1 month before the earthquake.

In the same way, we obtained the characteristics of $\Delta M_{\max }$ and $M_{\max }$ before the seven strong earthquakes in Southern California since 1980, as shown in Table 2.

From Table 2, we can summarize that for strong earthquakes with $\mathrm{M} \geq 6.5$ in Southern California, the interval between $\Delta M_{\max }$ and the forthcoming strong earthquake is from 3 to 27 months, and the average of $\Delta \tau_{1}$ is about 9 months. The interval between $M_{\max }$ and the forthcoming strong earthquakes is from 1 to 71 months, and the average of $\Delta \tau_{2}$ is 22.4 months.

Table 2 also shows that the critical scale for different strong earthquakes is different. The largest scale is $8^{\circ} \times 8^{\circ}$ for the Loma Prieta M 7.0 earthquake, while for the Hector Mine M 7.1 earthquake, the critical scale is only $3^{\circ} \times 3^{\circ}$. Why the critical scales for different earthquakes with similar magnitude differ so much is reserved as a question. 
Table 2

Characteristics of $\Delta M_{\max }$ and $M_{\max }$ before strong earthquakes in Southern California since 1980.

\begin{tabular}{|c|c|c|c|c|c|}
\hline Date & Epicenter and location & Magnitude & $\begin{array}{c}\text { Date 'of } \Delta M_{\max } \text { ' } \\
\Delta \tau_{1} \text { (month) }\end{array}$ & $\begin{array}{c}\text { Date of } M_{\max } / \\
\Delta \tau_{2} \text { (month) }\end{array}$ & $\mathrm{m}$ \\
\hline 1983.5.2 & $\left(36.23^{\circ} \mathrm{N}, 120.32^{\circ} \mathrm{W}\right)$ Coalinga & 6.7 & $1983.1 .1 / 4$ & 1983.4.1/1 & 3 \\
\hline 1987.11.24 & $\left(33.01^{\circ} \mathrm{N}, 115.85^{\circ} \mathrm{W}\right)$ Superstition Hills & 6.6 & 1987.6.24/5 & 1987.5.24/6 & 4 \\
\hline 1989.10 .18 & $\left(37.04^{\circ} \mathrm{N}, 121.88^{\circ} \mathrm{W}\right)$ Loma Prieta & 7.0 & 1987.7.18/27 & $1987.05 .18 / 29$ & 8 \\
\hline 1992.6.28 & $\left(34.20^{\circ} \mathrm{N}, 116.44^{\circ} \mathrm{W}\right)$ Landers & 7.3 & $1992.03 .28 / 3$ & 1992.05.28/1 & 4 \\
\hline 1994.1.17 & $\left(34.21^{\circ} \mathrm{N}, 118.54^{\circ} \mathrm{W}\right)$ Northridge & 6.6 & $1993.06 .17 / 7$ & $1993.03 .17 / 10$ & 5 \\
\hline 1999.10.16 & $\left(34.59^{\circ} \mathrm{N}, 116.27^{\circ} \mathrm{W}\right)$ Hector Mine & 7.1 & 1999.02.6/8 & 1996.07.16/39 & 3 \\
\hline 2003.12 .22 & $\left(35.7^{\circ} \mathrm{N}, 121.1^{\circ} \mathrm{W}\right)$ San Simeon & 6.5 & 2003.01.22/11 & 1998.01.22/71 & 5 \\
\hline
\end{tabular}

Note: $\Delta M_{\max }$ is the maximum value of the modulus of increment of state vector.

$M_{\max }$ is the maximum value of the modulus of the State Vector.

$\Delta \tau_{1}$ is the interval between time of the modulus of the maximum increment State Vector and the occurrence time of the forthcoming earthquake.

$\Delta \tau_{2}$ is the interval between time of the modulus of the maximum State Vector and the occurrence time of the forthcoming earthquake.

$m$ is the number of grids along latitude or longitude direction of the square region.

\section{Comparison of the Characteristics of the LURR and the State Vector}

Table 1 and Table 2 list the characteristics of LURR and State Vector anomalies before 7 strong earthquakes with $M \geq 6.5$ in Southern California since 1980. Here we compare three kinds of intervals, $\Delta \tau, \Delta \tau_{1}$ and $\Delta \tau_{2}$, before each strong earthquake. $\Delta \tau$ denotes the interval between the time of the peak LURR and the occurrence time of the forthcoming earthquake, $\Delta \tau_{1}$ is the interval between the time of the modulus of the maximum increment State Vector and the occurrence time of the forthcoming earthquake, and $\Delta \tau_{2}$ is the interval between the time of the modulus of the maximum State Vector and the occurrence time of the forthcoming earthquake.

Figure 5 shows that the maximum LURR values appear within 12 months before the Superstition Hills, Loma Prieta, Landers and Hector Mine earthquakes. The maximum $M$ values appear within 12 months before the Coalinga, Superstition Hills, Landers and Northridge earthquakes, while the maximum $\Delta M$ values appear within 12 months before Coalinga, Superstition Hills, Landers, Northridge, Hector Mine and San Simeon earthquakes. The above results suggest that the $\Delta M$ parameter is more valid for earthquake prediction within 12 months, than the $M$ parameter, and for almost half of the earthquakes (e.g., Superstition Hills, Landers, Northridge), the LURR and State Vector methods both work well.

In order to provide a simple and easy understanding of the effects of LURR and State Vector in time forecasting, we draw the spectrum of $\Delta \tau, \Delta \tau_{1}$ and $\Delta \tau_{2}$ in Figure 6 . We can see from this figure that $4 / 7$ of $\Delta \tau$ distribute from 9 to 13 months, and the mean value of the dominant $\Delta \tau$ is 10.7 months; $4 / 7$ of $\Delta \tau_{1}$ distribute mainly from 3 to 11 months, and the mean value of $\Delta \tau_{1}$ is 4.7 months; $4 / 7$ of $\Delta \tau_{2}$ distribute from 1 to 10 months, and the mean value of $\Delta \tau_{2}$ is 4.5 months. The results imply that the State Vector is a valid 


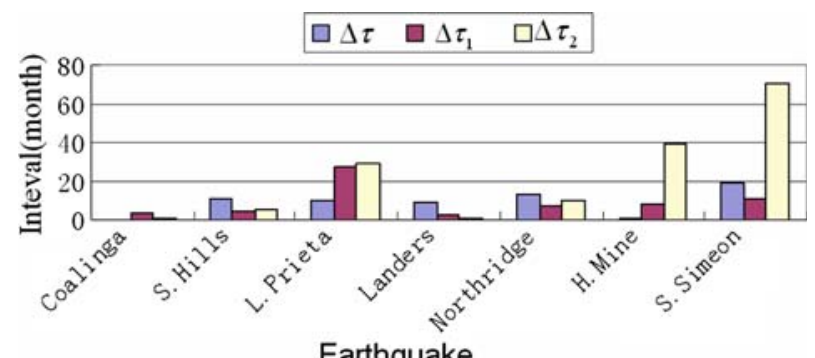

Figure 5

$\Delta \tau, \Delta \tau_{1}$ and $\Delta \tau_{2}$ for the strong earthquakes in Southern California since 1980.

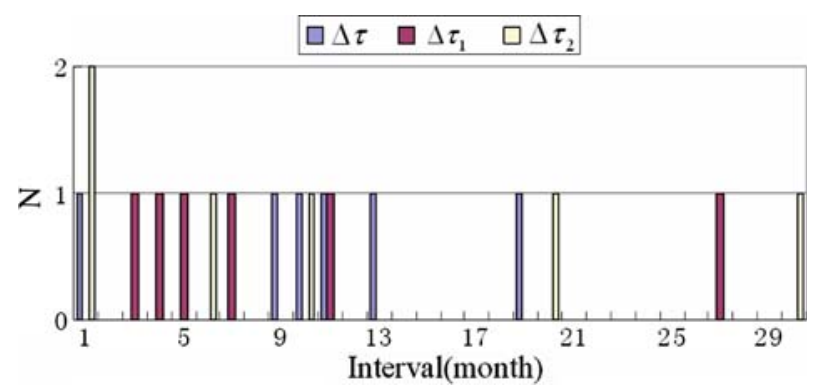

Figure 6

Spectrum of $\Delta \tau, \Delta \tau_{1}$ and $\Delta \tau_{2}$.

method for short-term earthquake forecasting, and the LURR is a valid method for medium-term earthquake forecast in Southern California since 1980. The $\Delta M$ parameter seems to be more stable than the $M$ parameter.

\section{Conclusions and Discussion}

There are only seven strong earthquakes with $M \geq 6.5$ in Southern California since 1980. From the above results, we can draw the following conclusions:

(1) LURR anomalies occurred before 6 earthquakes out of 7 and State Vector anomalies occurred before all of these 7 earthquakes.

(2) For LURR, the interval between the maximum $Y / Y_{c}$ value and the forthcoming earthquake ranges from 1 to 19 months, and the dominant mean interval is about 10.7 months. For the State Vector method, the interval between the maximum modulus of the increment State Vector and the forthcoming earthquake ranges from 3 to 27 months, but the dominant mean interval between the occurrence time of the maximum State Vector anomaly and the forthcoming earthquake is about 4.7 months. 
(3) The minimum valid space window scale for the LURR and State Vector is a circle with a radius of $100 \mathrm{~km}$ and a square of $3^{\circ} \times 3^{\circ}$, respectively.

From the above results, the State Vector method seems to be more effective for shortterm earthquake prediction than the LURR method, however the LURR method is more effective for location prediction than the State Vector method.

The above conclusions are based on limited earthquake cases in Southern California. Are they tenable for other strong earthquakes in other regions? YIN et al. (2004a,b) and Wu et al. (2006) studied the earthquake cases in China, and their results show that several months before many strong earthquakes, significant State Vector anomalies did occur. Yu et al. (2004) also confirmed the phenomena of the State Vector anomaly before rock failure by rock mechanical testing, which proved the solid mechanical base for the State Vector method. However, more earthquake cases should be studied before drawing the confirmed conclusions.

Some questions are left behind in this study, such as why the critical scales for different earthquakes with similar magnitude differ so much. Is the square region the best to calculate parameters related to the State Vector? How should the threshold for the State Vector calculation be chosen? Is the subdivision of Southern California into 11 areas reasonable? There are many details to be concerned with and statistical checks to be done before the LURR and the State Vector could be used as earthquake predictors.

\section{Acknowledgements}

The authors gratefully acknowledge the support from Special Funds for Major State Basic Research Project under Grant No.2004 CB418406, 004DKA50740, 2002CB412706, NSFC under Grant Nos. 10232050, 10572140, the Informatization Construction of Knowledge Innovation Projects of the Chinese Academy of Sciences "Supercomputing Environment Construction and Application" (INF105-SCE-2-02) and Chinese Joint Seismological Foundation (305016). We also express our thanks to ANSS for earthquake data.

We especially thank the revisers who raised questions and offered good suggestions to improve our paper in grammar, organization, logic, etc.

\section{REFERENCES}

Bullen, K.E. and Bolt, B.B., An Introduction to the Theory of Seismology (Cambridge University Press, Cambridge Press 1985).

Gutenberg, B. and Richter, C.F. (1956), Magnitude and energy of earthquakes, Annali di Geofisica 9, 1-15. Kanamori, H. and Anderson, D.L. (1975), Theoretical basis of some empirical relations in seismology, Bull. Seismol. Soc. Am. 65(5), 1073-1095.

Mei, S.R., Feng, D.Y., Zhang, G.M., Zhu, Y.Q., Gao, X. and Zhang, Z.C., Introduction to Earthquake Prediction in China (Beijing, Seismological Press, 1993) 35-36 (in Chinese with English Abstract). 
Mora, P., Place, D., Wang, Y.C., Yin, X.C., Peng, K.Y., and Weatherley, D. (2000a), Earthquake Forecasting: Retrospective Studies in Australia - the Newcastle and Burra Earthquakes and Numerical Simulation of the Physical Process, AEES (Australian Earthquake Engineering Society) Annual Meeting, November, 2000, Hobart, Australia.

Mora, P., Place, D., Wang, Y.C., and Yin, X.C. (2000b), Simulation of Load-Unload Response Ratio in the Lattice Solid Model, AGU (American Geophysical Union) 2000 fall Meeting, San Francisco, 10-17, December 2000.

Mora, P., Wang, Y.C., Yin, C., Place, D., and Yin, X.C. (2002), Simulation of the Load-Unload Response ratio and critical sensitivity in the lattice solid model, Pure Appl. Geophys. 159(10), 2525-2536.

ReIChl, L.E. (1980), A Modern Course in Statistical Physics (University of Texas 1980).

WANG, Y.C., YIN, X.C., and PENG, K.Y. (1999), Numerical simulation on Load/Unload Response Ratio theory, Chinese J. Geophys. 42(4), 527-536.

Wu, Y.J., Zhang, Y.X., and Yin, X.C. (2006), Characteristics of State Vector anomaly before 25 earthquakes $(M \geq 6.8)$ in China mainland since 1970, Earthquake (in Chinese with English abstract) 26 (2), 61-67.

YIN, X.C. (1987), A new approach to earthquake prediction, Earthq. Res. in China 3, 1-7 (in Chinese with English abstract).

YIN, X.C. and YIN, C. (1991), The precursor of instability for nonlinear systems and its application to earthquake prediction, Science in China 34, 977-986.

Yin, X.C., Chen, X.Z., Song, Z.P., and Yin, C. (1995), A new approach to earthquake prediction: The Load Unload Response Ratio (LURR) theory, Pure Appl. Geophys. 145, 701-715.

YIN, X.C., WANG, Y.C., Peng, K.Y., and BAI, Y.L. (2000), Development of a new approach to earthquake prediction: Load/Unload Response Ratio (LURR) theory, Pure Appl. Geophys. 157, 2365-2383.

Yin, X.C., Mora, P., Peng, K.Y., Wang, Y.C., and Weatherly, D. (2002a), Load-Unload Response Ratio and accelerating moment/energy release, critical region scaling and earthquake prediction, Pure Appl. Geophys. 159, 2511-2514.

Yin, X.C., Zhang, H.H., Peng, K.Y., Wang, Y.C., Yin, C., and Zhang, Y.X. (2002b), Scaling of LURR Critical Region, $3^{\text {rd }}$ ACES Workshop, May 5-10, 2002, Island of Maui, Hawaii, U.S.A.

Yin, X.C., Yu, H.Z. and Zhang, Y.X. (2004a), State Vectors-A new method to analysis seismicity, Earthq. Res. in China 18(3), 263-270.

Yin, X.C., Yu, H.Z., Kunshenko, V., Xu, Z.Y., Wu, Z.S., Li, M., Peng, K.Y., Elizarov, S., and Li, Q. (2004b), Load-Unload Response Ratio (LURR), accelerating energy release (AER) and State Vector evolution as precursors to failure of rock specimens, Pure Appl. Geophys. 161, 2405-2416.

Yu, H.Z., Yin, X.C., Zhang, Y.X. et al. (2004), Experimental study of State Vector, Earthquake 24(3), 1-7 (In Chinese with English Abstract).

Zhang, H.H., Yin, X.C., and LiAng, N.G. (2005), Statistic study of LURR anomaly temporal scale before moderately strong earthquakes in Chinese mainland, Earthq. Res. in China 21, 486-495.

Zhang, Y.X., YIN, X.C., and PENG, K.Y. (2004), Spatial and temporal variation of LURR and its implication for the tendency of earthquake occurrence in Southern California, Pure Appl. Geophys. 161, 11-12, 2359-2367.

Zhang, Y.X, Yin, X.C. et al. (2006), LURR and the San Simeon M 6.5 earthquake in 2003 and the seismic tendency in CA, Pure Appl. Geophys. 163, 2343-2351.

Zhuang, J.C. and Yin, X.C. (1999), Random distribution of the Load/Unload Response Ration (LURR) under assumptions of Poisson model, Earthq. Res. in China 15, 128-138.

Zоваск, M.L. (1992), First- and second-order patterns of stress in the lithosphere: The world stress map project, J. Geophys. Res. 97, 11,703-11,728.

(Received September 6, 2006, revised March 31, 2007, accepted August 30, 2007)

To access this journal online: www.birkhauser.ch/pageoph 